\title{
Interpretation of Dispersion Phenomena in Grunwald-Winstein Correlation for Solvolyses of Naphthoyl Chloride
}

\author{
Zoon Ha Ryu,, Chang-Suk Ju, Dae Dong Sung, ${ }^{\dagger}$ Nak Chang Sung, and T. William Bentley ${ }^{\sharp}$ \\ Deparment of Chemistry: Dong-Eu Linersity, Pusan 614-714, Korea \\ - Department of Chemistry: Dong-A Ciniversity, Pusan 604-714, Korea

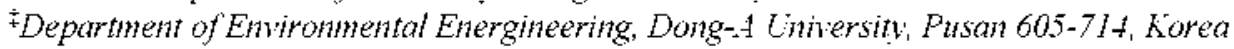 \\ \$Department of Chemistry, Lniversity of Wales, Swansea, Singleton Park Sinchea, SA2 8 PP, UK \\ Received October 26, 2001
}

\begin{abstract}
Solvolyses rate constant of 1 - and 2- naphthoyl chlorides ( 1 and 2 ) are reported for aqueous binary mixtures with methanol. ethanol. fluorinated alcohol. acetonitrile and dioxane. Kinetic solvent isotope effects (KISE) in methanol and product selectivities (S) of 2-naphthoyl chloride (2) in alcohol-water are also reported. Dispersions in Grunwald-Winstein correlations $(\mathrm{r} \leq 0.90 \mathrm{l})$ are discussed by multiple regression analysis incorporating ionizing power $\left(\mathrm{Y}_{\mathrm{C}: \mathrm{i}}\right)$ scale and rate-rate profiles. Major causes for these phenomena are investigated as an aromatic ring solvation effects. in conjunction with weakly nucleophilic solvation effects ( $\mathrm{S}_{*} 2$ character) for solvolyses of 1 and for solvoly ses of 2 . as dual reaction channels. described as $\mathrm{S}_{\mathrm{N}} \mathrm{I}-\mathrm{S}_{\mathrm{S}}, 2$ and $\mathrm{S}_{i} \mathrm{~N}-\mathrm{S}_{\mathrm{i}} 2$ processes. Distinct border lines between the two pathways are derived from solvolyses rates of 2 in 18 solvent using the results of $\log \left(k / k_{0}\right)=m \mathrm{Y}_{[\mathrm{C}}+\mathrm{N}_{\mathrm{T}}+\mathrm{hL}$ plot with values of 1.13 for $\mathrm{m} .0 .37$ for $/$ and 0.15 for $\mathrm{h}$ value in $\mathbf{5}$ aqueous fluorinated alcohol mixtures. Using rate-product correlation, the validity of a third order model based on a general base catalyzed by solvent and contribution from these rate constants. $k_{a \mathrm{a} \text {, }} k_{\text {aw }}$ and $k_{\mathrm{w} \text { a }}$. are investigated for $S_{i} \mathrm{~N} / \mathrm{S}_{:} \cdot 2$ solvoly ses of 2 favored in more rich alcohol media and gradual addition of water to alcohol solvent shows a great shift away from stoichiometric solvation to predominantly medium effects. Rate-rate correlation between solvolyses of 2 and trimethyl acetylchloride (5) with alkyl group in the 29 aqueous solvent mixtures shows appreciable linearity (slope $=0.84, \mathrm{r}=0.987$ ). caused by the same pathway ( $\mathrm{S}_{\mathrm{i}} \mathrm{l}-\mathrm{S}_{\mathrm{N}} \cdot 2$ process). even if this correlation coincides with appreciable dispersion (different solvation effect).
\end{abstract}

Keywords : Solvolysis. Dispersion. Grunwald-Winstein correlation.

\section{Introduction}

Dispersion into separate lines in correlation of the rates of solvolyses of RX substrate in various aqueous solvent mixtures has been handled in early treatments using the Grunwald-Winstein equation (1). 1.2

$$
\log \left(k / k_{\mathrm{c}}\right)=\mathrm{mY}+\mathrm{c}
$$

And dispersed Grunwald-Winstein relations have recently been interpreted as specific solvent effects according to effective nucleophilic participation ${ }^{3-5}$ by solvent molecules from rear side in transition state (TS). These results have been evaluated by the extended Grunwald-Winstein equation (2) ${ }^{5.6}$ considering nucleophilic assistance from a solvent.

$$
\log \left(k / k_{\mathrm{c}}\right)=\mathrm{N}_{\mathrm{T}}+\mathrm{mY}_{\mathrm{Cl}}+\mathrm{c}
$$

In equation (1) and (2), $k$ and $k_{\circ}$ are the rates of solvolyses in a given solvent and in $80 \%$ ethanol. respectively: / is the sensitivity to charges in solvent nucleophilicity $\left(\mathrm{N}_{\mathrm{T}}\right.$ : base on the solvolyses of S-methyl dibenzothiophenium ion $\left.{ }^{7}\right): \mathrm{m}$ is the sensitivity to changes in ionizing power ( $Y$ : based on the solvoly'ses of tert-butyl chloride' ${ }_{\mathrm{C}}$ : those of 1-adamantyl cloride ${ }^{2} 3$ ): and $c$ is a residual term.

In consideration of the other factors. Bentley ${ }^{8}$ and $\mathrm{Liu}^{5}$ have suggested that a major cause of dispersion is solvation differences between the aromatic ring of a substrate being studied and the alkyl group of a standard substrate (ionzation power). Kevill ${ }^{10}$ proposed the aromatic ring parameter (I) to be considered as a resonance interaction between the reaction site and aryl- $\pi$-system and addition of $\mathrm{hI}$ term to equation (1) and (2) led to equation (3) and (4)."

$$
\begin{gathered}
\log \left(k / k_{\mathrm{c}}\right)=\mathrm{mY}+\mathrm{hI}+\mathrm{c} \\
\log \left(k / k_{\mathrm{c}}\right)=\mathrm{N}_{\mathrm{T}}+\mathrm{mY}_{\mathrm{Cl}}+\mathrm{hI}+\mathrm{c}
\end{gathered}
$$

$h$ represents the sensitivity of solvolyses to changes in I parameter.

The similiar model based on the rates of solvolyses of 2chloro-2-(m-chlorophenyl)adamantane ${ }^{\vartheta}(\boldsymbol{t})$. termed the $Y_{\text {Encl }}$ scales which was recognized as a new $Y$ scale involving those of corresponding I parameter. was also represented by Liu. ${ }^{9}$ and then equation (5) and (6) can be handled in the same sense as equation (3) and (4).

$$
\begin{gathered}
\log \left(k / k_{\mathrm{c}}\right)=\mathrm{m} \mathrm{Y}_{\mathrm{EnCl}}+\mathrm{c} \\
\log \left(k / k_{\mathrm{c}}\right)=\mathrm{mY}_{\mathrm{BnCl}}+\mathbb{N}_{\mathrm{T}}+\mathrm{c}
\end{gathered}
$$

More recently Fujio' 2 et al have also emphasized the signification of solvation on charge-delocalized TS in benzylic solvolyses.

On the other hand product selectivity (S) for solvolyses of acid chloride giving an ester and acid products in alcohol- 
water mixtures can be defined by equation (7), ${ }^{13}$ which relates to the molar solvent ratio, for product study.

$$
S=[\text { ester }]_{\text {prod }} /[\text { acid }]_{\text {prod }} \times[\text { water }]_{\text {selv. }} /[\text { alcohol }]_{\text {so }]}
$$

In general as water is added to alcohol. the variation of $S$ value (except for the case of more rich water-rich solvents which led to a poor solubility of substrate) have shown either a gradual increase $e^{4,14.15}$ or a decrease $e^{16}$ or a constant value..$^{17,18 a}$ but occasionally maximum value of $S^{18}$ in specific solvent composition have been observed for a several substrates with dispersion in Grunwald-Winstein plots. and then these results have been accepted as the identification for dual reaction channels.

Solvolyses of various acid chlorides in binary solvent mixtures. which are one of the transfer reactions of an acyl group with variations ${ }^{19}$ from carbonyl addition ${ }^{4.3(13) 1}$ to $S_{: 1}$ mechanism (dissociative pathway with the acylium ion. $\left.\mathrm{RCO}^{-}\right)^{\hat{\imath}}$ according to the changes of solvent composition. have been studied extensively. ${ }^{23}$

Our research has been conducted for the purpose of finding out the major reason why solvolytic reaction for 1 (1) and 2-1laphthoyl chloride (2) in aqueous solvent mixtures display phenomena of dispersion in a Grunwald-Winstein correlation. Such phenomena are discussed by various Grunwald-Winstein type correlation analyses [equation (26)] and rate-rate profiles. And we have attenipted to inquire into mechanism in terms of the variation $S$ values as the changes in solvent composition of alcohol-water mixtures. the additional kinetic data for solvolyses of 2 in aqueous fluorinated alcohol system and the kinetic solvent isotope effect (KISE) in methanol. For solvolyses of $\mathbf{2}$ in more richalcohol media. the possibility for application of third order model based on a general base catalyzed by a solvent is also deduced.

\section{Results and Discussion}

Rate constants for solvolyses of $\mathbf{1}$ and $\mathbf{2}$ in aqueous binary mixtures with methanol. acetone. acetonitrile and dioxane at<smiles>O=C(Cl)c1cccc2ccccc12</smiles>

1<smiles>Clc1cccc(C2(Cl)C3CC4CC(C3)CC2C4)c1</smiles>

4<smiles>ClC(c1ccccc1)c1ccccc1</smiles>

7<smiles>O=C(Cl)c1ccc2ccccc2c1</smiles>

2<smiles>CC(C)(C)C(=O)O</smiles><smiles>[Y]c1ccc(C(=O)OCc2ccccc2)cc1</smiles>

6 a : $X=I I$ $6 \mathrm{~b}: \mathrm{X}=\mathrm{P}_{-}-\mathrm{CH}_{3}$ $6 \mathrm{c}: \mathrm{X}=\mathrm{P}-\mathrm{Cl}$ $6 \mathrm{~d}: \mathrm{X}=\mathrm{P}-\mathrm{NO}_{2}$ 6 e : $\mathrm{X}=\mathrm{P}-\mathrm{OCH}_{3}$<smiles>O=P(Cl)(Oc1ccccc1)Oc1ccccc1</smiles>

8
Scheme 1

$25^{\circ} \mathrm{C}$ are given in Tables 1 and 2 . and additional data in fluorinated alcohol system is shown in Table 1 .

Grunwald-Winstein parameter correlation. The solvent effect for solvolyses reaction of $\mathbf{1}$ and $\mathbf{2}$ in a wide variety of solvents were analyzed by using the Grunwald-Winstein equation (l). The $\mathrm{Y}_{C l}$ plots for these solvolyses showed no single linear correlations $(\mathrm{r} \leq 0.90 \mathrm{l})$ because of the dispersion patterns for different binary solvent mixtures typically Figure 1 for $\mathbf{2}$ and Table 3. Good correlations for each binary solvent mixtures was obtained, respectively (for solvolyses of $\mathbf{2}$ in binary solvent mixtures containing higher water content than solvolyses of $\mathbf{1}$ ).

As shown in Table 3. according to the results for the application of various Gnuwald-Winstein parameter [equation

Table 1. First-order rate constant $\left(k \times 10^{3} \mathrm{~s}^{-1}\right)$ for solvoly ses of 1 and 2 in aqueous solvent mistures at $25^{\circ} \mathrm{C}^{\circ}$

\begin{tabular}{|c|c|c|c|c|c|}
\hline \multirow{2}{*}{ Solvent composition ${ }^{b}$} & \multicolumn{2}{|c|}{ methanol } & \multicolumn{2}{|c|}{ ethanol } & \multirow{2}{*}{$\begin{array}{c}\text { trifluoroethanol } \\
\mathbf{2} \\
\end{array}$} \\
\hline & 1 & 2 & 1 & 2 & \\
\hline 100 & $16.1 \pm 0.2$ & $4.83 \pm 0.03$ & $2.10 \pm 0.03$ & $0.918 \pm 0.05$ & \\
\hline 97 & & & & & $10.1 \pm 0.1$ \\
\hline 90 & $39.5 \pm 0.3$ & $8.64 \pm 0.01$ & $6.46 \pm 0.02$ & $1.99 \pm 0.01$ & $17.9 \pm 0.4$ \\
\hline 80 & $118 \pm 3$ & $13.8 \pm 0.2$ & $16.1 \pm 0.04$ & $3.03 \pm 0.01$ & \\
\hline 70 & $259 \pm 2^{4 i}$ & $22.3 \pm 0.1^{d t}$ & $28.0 \pm 0.2$ & $4.80 \pm 0.05$ & $40.5 \pm 0.3$ \\
\hline 60 & $757 \pm 2^{e}$ & $42.1 \pm 0.6^{e}$ & $101 \pm 3$ & $8.77 \pm 0.01$ & \\
\hline 30 & & $79.7 \pm 0.3^{r}$ & $303 \pm 4$ & $19.6 \pm 0.2$ & $76.1 \pm 0.2$ \\
\hline 40 & & $179 \pm 1.0^{r}$ & & $47.7 \pm 0.1^{g}$ & $50 \% \mathrm{HFIP}^{\prime}$ \\
\hline 30 & & & & $191 \pm 1.0^{\prime \prime}$ & $125 \pm 4^{\text {c.e.s }}$ \\
\hline
\end{tabular}

"Determined conductimetrically at least in duplicate. typically injected $10 \mu \mathrm{L}$ of $\mathrm{I}^{\circ} \mathrm{\sigma}(\mathrm{w}$ (w) substrate in dry acetonitrile into the kinetic apparatus with a turbo-stirrer containing $5 \mathrm{~mL}$ of each solvent mixture: errors shown are standard deviations. "Percentage of volume by' alcohol (vvolo). 'Percentage of weight by fluoroalcohol (water contents were confirmed as errors $0.3 \%$ by using Karl Fischer Titrator). "Injected $10 \mu \mathrm{L}$ of $0.5^{\circ}$ o (wi w) substrate in dry'

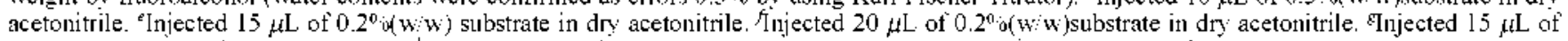

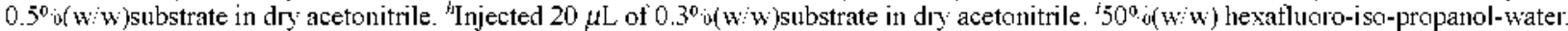


Table 2. First-order rate constant $\left(k \times 10^{4} \mathrm{~s}^{-1}\right)$ for solvolyses of 1 and 2 in aqueous solvent mistures at $25^{\circ} \mathrm{C}^{a r}$

\begin{tabular}{|c|c|c|c|c|}
\hline \multirow{2}{*}{$\begin{array}{c}\text { Solvent } \\
\text { composition }\end{array}$} & \multicolumn{2}{|c|}{ acetone } & \multirow{2}{*}{$\frac{\text { acetonitrile }}{2}$} & \multirow{2}{*}{$\frac{\text { diosane }}{2}$} \\
\hline & 1 & 2 & & \\
\hline 90 & $2.68 \pm 0.06$ & $2.25 \pm 0.05$ & $1.27 \pm 0.23$ & $3.00 \pm 0.09$ \\
\hline 80 & $16.9 \pm 0.3$ & $5.77 \pm 0.01$ & $5.76 \pm 0.06$ & $6.87 \pm 0.08$ \\
\hline 70 & $77.6 \pm 0.2$ & $12.6 \pm 0.1$ & $15.6 \pm 0.07$ & $13.0 \pm 0.1$ \\
\hline 60 & $309 \pm 4$ & $29.0 \pm 0.01$ & $34.9 \pm 0.21$ & $27.7 \pm 0.3$ \\
\hline 50 & $1150 \pm 10$ & $79.2 \pm 0.7$ & $81.5 \pm 0.6$ & $68.2 \pm 2.9$ \\
\hline 40 & & $233 \pm 4^{\circ}$ & $219 \pm 9$ & $201 \pm 6$ \\
\hline 30 & & $900 \pm 7^{\circ}$ & $747 \pm 48$ & $773 \pm 16$ \\
\hline
\end{tabular}

"Determined as described footnote a in Table 1 except for the condition of reaction injected $5 \mu \mathrm{L}$ of $1^{\circ}$. o(w w) substrate in dry acetonitile into the linetic apparatus containing $2.5 \mathrm{~mL}$ of each solvent. ${ }^{b}$ Percentage by folume of aprotic solvent $\left(F^{0}, 0\right)$. "Injected $10 \mu \mathrm{L}$ of $0.5^{\circ} .0(\mathrm{w} / \mathrm{w})$ substrate in dry acetonitrile.

(1)-(6)]. correlations of $\log \left(k / k_{0}\right)$ for solvoly ses of 1 and 2 by using equation (4) and (6) are much better for all solvent systems chosen ( $r \geq 0.982$. Figure 2$)$ than those by the other equations. Consequently, the phenomenon of dispersion (no single correlation) was indicated to be related to an aromaticring factor, considering the stabilization of the transition state (TS) through cationic charge-delocalization ( $\mathrm{S}_{\mathrm{K}} \mathrm{l}$ character). as well as nucleophilicity term of the solvent.

The m-value analyzed by using equation (3)-(6), which was included I or $Y_{\text {Bncl }}$ parameter. for solvolyses of 1 were greater than these values obtained by The original GrunwaldWinstein equation (1). Such results are analogous to recent results for $S_{X} 1$-solvolyses of 1.1-diaryl-2.2,2-trifluoroethyl chlorides studied by Fujio' and colleagues. ${ }^{-2-1}$ These may be additional evidence that solvolyses rate of $\mathbf{1}$ is concerned with resonance-stabilized carbocation in TS and it is mirrored in the degree of the stablization of TS by the formation of resonance between the aromatic ring and the reaction center, as shown Scheme 2 and, is significant for deciding the magnitude of the m-rales. known as the creation of mechanism. The possibility for charge delocalization over the naphthyl ring in the solvolytic TS of 1 was already

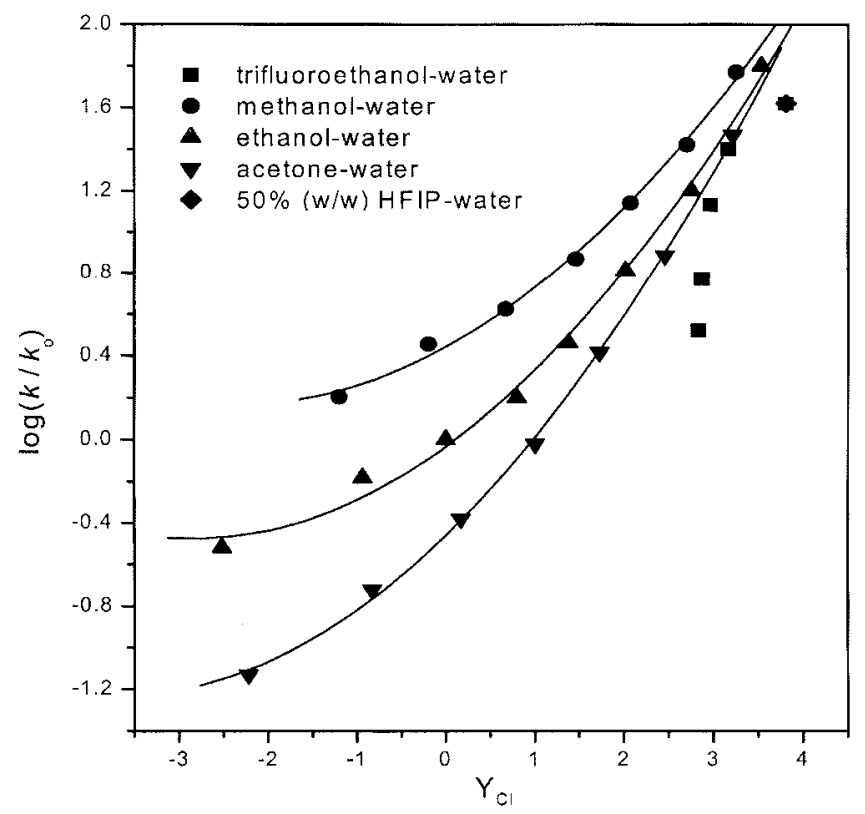

Figure 1. Correlation of logarithms of rate constant for solvolyses of 2 at $25^{\circ} \mathrm{C}$ against $\mathrm{Y} \mathrm{c}$

proposed by Liu's $a b$ initio calculation ${ }^{25}$ of the charge distribution in the acylium ion.

Whereas. in the case of $\mathbf{2}$, the m-values are in total, little changed according to the change in Grunwald-Winstein equation applied, compared with solvolyses of 1 . These can be explained as the relative reduction of the contribution from resonance effect on the m-values.

Under the condition of the correlation coefficient $(r>$ 0.975 ) accepted as correlationship in this work, we can also see in Tables 3 and 4 that the range of variety of the m-value in solvoly ses of $\mathbf{1}$ were a greater than these values of $\mathbf{2}$ and in the case of $l$-values. even if the large value of 0.68 for 1 appeared, the $/ / \mathrm{m}$ - and h-values of $\mathbf{1}$ and $\mathbf{2}$ analyzed in terms of equation (4) were shown to be a very similar and/on equal values $(/ / \mathrm{m}=0.96$ for 1 and 0.98 for 2 . respectively and $\mathrm{h}=1.22$ for 1 and 2 ). but when analyzed using equation (6).

Table 3. Correlation analyses of $\left.\log (k / k,)_{0}\right) 1$ and 2 with single (dual) or multiple parameter Grunwald-Winstein equation [(1)-(6)] ${ }^{s}$

\begin{tabular}{|c|c|c|c|c|c|c|c|c|}
\hline Substrate & Parameters & Solvent & n & $r$ & $\mathrm{ml}$ & I & h & c \\
\hline \multirow[t]{6}{*}{1} & $\mathrm{Y}_{\mathrm{Cl}}$ & $\mathrm{All}^{\mathrm{b}}$ & 16 & 0.901 & 0.58 & & & 0.08 \\
\hline & $\mathrm{Y}_{\mathrm{Cl}, \mathrm{I}}$ & $\mathrm{All}^{\mathrm{b}}$ & 11 & 0.977 & 0.63 & & 1.81 & 0.08 \\
\hline & $\mathrm{Y}_{0,}, \mathrm{~N}_{\mathrm{T}}$ & $\mathrm{All}^{b}$ & 16 & 0.934 & 0.71 & 0.90 & & 0.25 \\
\hline & $Y_{0,}, N_{T} I$ & $\mathrm{All}^{b}$ & 11 & 0.982 & 0.71 & 0.68 & 1.22 & 0.22 \\
\hline & $\mathrm{Y}_{\mathrm{Br}: 1}$ & $\mathrm{All}^{\mathrm{b}}$ & 13 & 0.985 & 0.71 & & & -0.01 \\
\hline & $\mathrm{Y}_{\mathrm{Bn}, \mathrm{l}}, \mathrm{N}_{\mathrm{T}}$ & $\mathrm{All}^{\mathrm{b}}$ & 13 & 0.990 & 0.73 & 0.25 & & 0.03 \\
\hline \multirow[t]{6}{*}{2} & $\mathrm{Y}_{\mathrm{O}}$ & $\mathrm{All}^{\mathrm{b}}$ & & 0.899 & 0.39 & & & 0.07 \\
\hline & $\mathrm{Y}_{\mathrm{Cl}, \mathrm{I}}$ & $\mathrm{All}^{\mathrm{b}}$ & 18 & 0.902 & 0.37 & & 0.29 & 0.02 \\
\hline & $\mathrm{Y}_{0,}, \mathrm{~N}_{\mathrm{T}}$ & $\mathrm{all}^{\mathrm{b}}$ & 27 & 0.932 & 0.49 & 0.31 & & 0.16 \\
\hline & $Y_{0,}, N_{T} I$ & $\mathrm{All}^{\mathrm{b}}$ & 18 & 0.982 & 0.49 & 0.48 & 1.22 & 0.19 \\
\hline & $\mathrm{Y}_{\mathrm{BnCl}}$ & $\mathrm{All}^{\mathrm{b}}$ & 14 & 0.939 & 0.39 & & & 0.08 \\
\hline & $\mathrm{Y}_{\mathrm{Bn} \mathrm{C},}, \mathrm{N}_{\mathrm{T}}$ & $\mathrm{all}^{b}$ & 14 & 0.987 & 0.52 & 0.45 & & 0.09 \\
\hline
\end{tabular}

"Perforned within the range of solvent parameter reported till now according to solvent composition (refs $2,7.9$ and 10 ). ${ }^{\circ}$ For all solvent sustems chosen in this work as shown in table $l$ and 2 . "For methanol-water solvent mistures. "For ethanol-water solvent mixtures. ${ }^{2}$ For acetone-water solvent mixtures. For fluorinated alcohol-water solvent mixtures. 


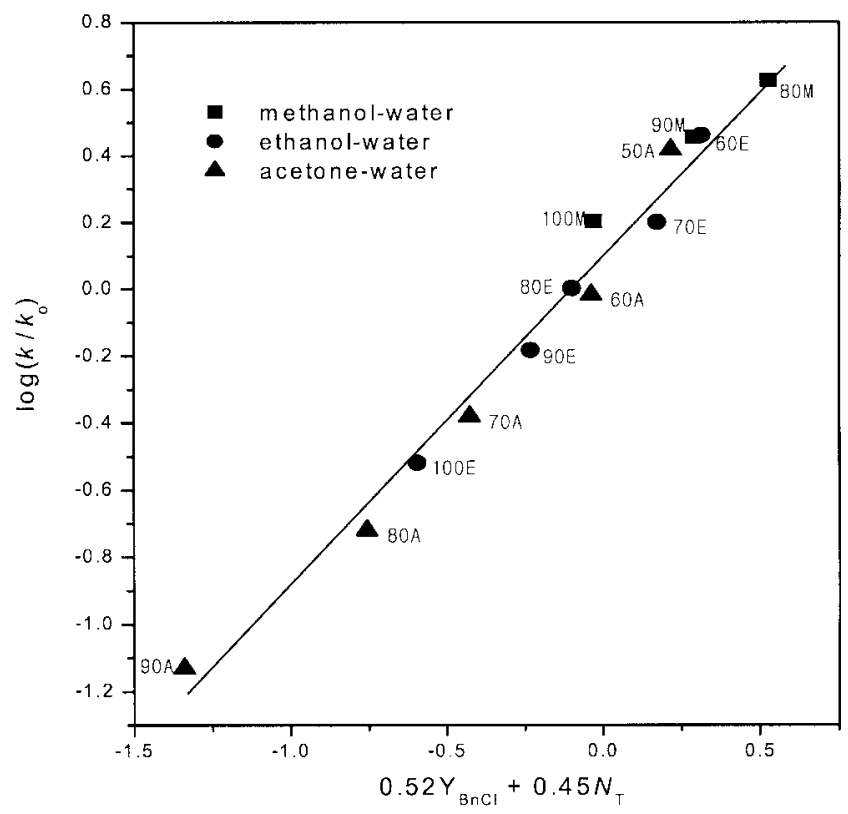

Figure 2. Correlation of logarithuns of rate for solvolyses of 2 in at $25^{\circ} \mathrm{C}$ against $\left(0.52 \mathrm{Y}_{\mathrm{Bn} C \mathrm{C}}+0.45 \mathrm{~N}_{\mathrm{T}}(\mathrm{T}=0.987)\right)$.

these values of 1 were shown to be smaller relative to 2 ( $/ /$ $\mathrm{m}=0.34$ for 1 and 0.87 for 2 ). Such phenomena may be attributed to the result caused by a peri-hydrogen effect of 1 on the reactivity for the nucleophilic substitution reaction: that is. a little shielding of the rear side of the reaction center ( $\alpha$-position) by a hydrogen atom, which was attached adjacent to the reaction center carbon, and was provided with a poor nucleophilic participation by molecule of solvent. compared to 2 with $\beta$-position of the reaction center. Accordingly, in cooperation with favorable electrostatic and charge delocalized solvation related nucleophilic attack. TS of carbocationic character in solvolyses of 1 may be stabilized more effectively than in those of 2 . although different results between equations were obtained.

From the mechanism point of view, Grunwald-Winstein correlation analyses of solvolyses rate of 1 in 13 solvents when using equation (6) gave a nicely linearity $(r=0.990)$ with $l=0.25$ and $\mathrm{m}=0.73$ and using equation $(4)$. the results obtained $(l=0.68 . \mathrm{m}=0.71$ and $\mathrm{h}=1.22)$ were very similar to that above for m-value. although the $/$-value was greater than in the case of equation (6). If we consider that the hvalue of corresponding cationic charge stabilization was also relatively greater value than the $l$-value enhancing and the results with $\mathrm{m}=0.63 \mathrm{~h}=1.81(\mathrm{r}=0.977)$ discussed by means of equation (3). (which was analogous to these values
Table 4. The susceptibility of each solvent parameter obtained from Grunwald-Winstein equation [ $(1)-(6)]^{\prime \prime}$

\begin{tabular}{cccc}
\hline Substrate & $\mathrm{m}$ & $l$ & $\mathrm{~h}$ \\
\hline $\mathbf{1}$ & $0.63-0.75$ & $0.25-0.68$ & $1.22-1.81$ \\
$\mathbf{2}$ & $0.49-0.52$ & $0.42-0.48$ & 1.22 \\
\hline
\end{tabular}

These results for solvolyses rates in aqueous fluorinated alcohols system are removed from correlation.

in $\mathrm{S}_{\mathrm{S}} \mathrm{I}$-solvolyses of $\mathrm{N}$-1-adamantyl- $\mathrm{N}$ - $p$-tolycarbamoyl chloride studied by Kevill' and D'Souza coworker). ${ }^{26}$ the correlation of solvolyses rate of 1 could be rationalized in term of an $\mathrm{S}_{\Downarrow} \mathrm{l}$ mechanism proceeding through a resonancestabilized carbocation intermediate with a weak nucleophilic solvation.

Conversely, for solvolyses of $2,0.52$ of the $\mathrm{m}$ - and 0.45 of the $/$-value in 14 solvents corresponding to less polar media $\left[>50 \%(\mathrm{v} / \mathrm{v})\right.$ aqueous solvent system allowed $\mathrm{Y}_{\mathrm{EnCl}}$ parameter] were obtained from a good correlation $(\mathrm{r}=0.987)$ by using equation (6) and the susceptibilities to equation (4) were also $l=0.48 \mathrm{~m}=0.49$ and $\mathrm{h}=1.22(\mathrm{r}=0.982)$. respectively. in 18 solvents including predominantly aqueous media. Perhaps these results for less polar media can be interpreted as possible evidence for $\mathrm{S}: 2$-type TS with charge delocalization and for 18 solvents, these results involving a higher h-value of 1.22. which was the same value as for solvolyses of 1 , and may suggest that dual reaction channels with resonance ionization pathway occur in solvolyses of 2 .

Fluorinated solvent. Fluorinated solvents known as favorable solvent systems for electrophilic solvation effect of solvolyses, were used for the solvolyses rates (Table 1). $97 \%(w / w)$ TFE-water and $40 \%(\mathrm{v} / \mathrm{v})$ ethanol-water solvent mixtures are represented as solvent system of similar ionizing power $\left(\mathrm{Y}_{\mathrm{Cl}}\right)$. but different nucleophilicities $\left(\mathrm{N}_{\mathrm{T}}\right)$, (97T; 2.83 of $\mathrm{Y}_{\mathrm{Cl} .}-3.30$ of $\mathrm{N}_{\mathrm{T}}$ and $40 \mathrm{E} ; 2.75$ of $\mathrm{Y}_{\mathrm{Cl}} .-0.74$ of $\left.\mathrm{N}_{\mathrm{T}}\right)^{2.7}$ and the values of the solvolyses rate ratio in these solvent mixtures, $\left[k_{4 \text { i }} / k_{97 \mathrm{~T}}\right]$ r. offer us useful information about not only the contribution from the solvent nucleophility (N) in solvolyses. but also the reaction mechanism. These ratio values and the solvolyses mechanism investigated by previous workers for typical compounds are shown in Table 5 compared with those for naphthoyl chloride (1 and 2).

According to the prediction of mechanism using table 5 . the case of 1 obtained as 3.6 could be $\mathrm{S}_{\mathrm{V}} \mathrm{L}$ mechanism. This is also consistent with a previous result discussed in terms of a Grunvald-Winstein correlation. Whereas. a 4.7-value of 2 , explained as dual reaction channel by a prior correlation analyses. displayed less than we expected. This means that

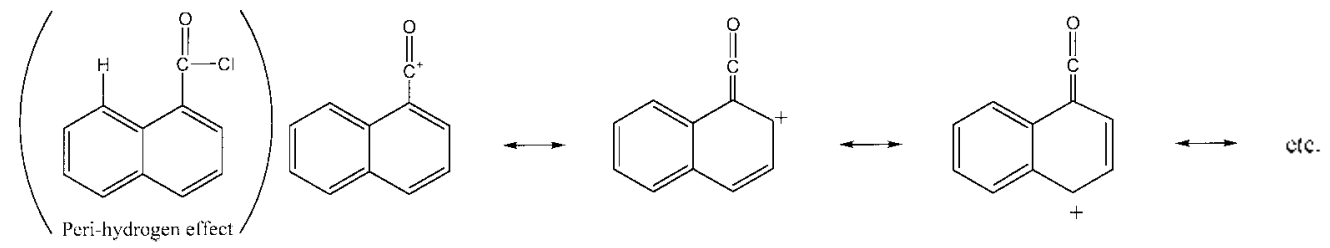


Table 5. Values of solvolyses ratios in $40 \%(\mathrm{v} / \mathrm{v})$ ethanol-water compound with $97 \%(\mathrm{w} / \mathrm{w})$ TFE-water at $25^{\circ} \mathrm{C}$ and the proposed mechanisinss

\begin{tabular}{|c|c|c|}
\hline Compound & {$\left[k_{40 \mathrm{E}} / k_{0 \mathrm{~T} T}\right] \mathrm{Y}^{\sigma}$} & mechanism \\
\hline 1 & $3.6\left(5^{\circ} \mathrm{C}\right)^{b}$ & \\
\hline 2 & $4.7^{c}$ & \\
\hline $6 a$ & $13^{i}$ & $\mathrm{~S}_{\mathrm{N}} 1 / \mathrm{S}_{\mathrm{N}} 2$ \\
\hline $6 d$ & $8.0 \times 10^{3}$ & $\mathrm{~S}_{\mathrm{N}} 2 / \mathrm{Ad}_{\mathrm{E}}$ \\
\hline $6 e$ & $5.0^{7}$ & $\mathrm{~S}_{\mathrm{N}} 1$ \\
\hline 7 & $0.18^{f}$ & $S_{N} 1$ \\
\hline 8 & $1.1 \times 10^{+}(0)^{g}$ & $\mathrm{~S}_{\mathrm{N}} 2 / \mathrm{Ad}_{\mathrm{E}}$ \\
\hline tert-BuCl & $11^{i t}$ & $\mathrm{~S}_{\mathrm{r}} 1$ \\
\hline $\mathrm{CH}_{2} \mathrm{OTs}$ & $500^{i}$ & $S_{* 2}$ \\
\hline
\end{tabular}

"Symbol represents a solvent of similar ionizing power $\left(\mathrm{Y}_{C \mathrm{C}}\right)$. Calculated from solvolvses rate at $5^{\circ} \mathrm{C}$ of corresponding $2.46 \times 10^{-1} \mathrm{~s}^{-1}$ for $4(0)$. ethanol-water and $6.92 \times 10^{-1} \mathrm{~s}^{-1}$ for $97^{\circ}$. nh ww) TFE-water (injected + $\mu \mathrm{L}$ of $0.1^{10} .(\mathrm{w} / \mathrm{w})$ substrate in dry acetonitrile into kinetic apparatus with turbo-stirrer containing $2.5 \mathrm{~mL}$ of eachsolvent mixtures). 'Data from Table 1. "Data from refs 18a and 27. "Data from refs 27 and 31. 'Data from ref. 28. Data from ref. 15b. "Data from ref. 29, 'Data from ref. 30.

$\left[k_{40 \mathrm{E}} / k_{97 \mathrm{~T}}\right]$ r ratio is the mechanistic tool unavailable for identifying the two different reaction channels occurring according to variation of solvent composition, but in $40 \mathrm{E}$ and 97T of corresponding to the range of polar media. this value of 4.7 can be responsible for $\mathrm{S}: 1$ solvolyses. Considering the ratio of these for $6 a^{18.27}$ which is similar for tert-butyl chloride but with a different reaction pathway as shown in table 5 , we could reasonably accept the reaction pathway for $\mathbf{2}$ as a dual process

Evaluation of the rate of solvolyses of $\mathbf{2}$ in 5 fluorinated alcohol systems on the basis of equation (2) gave a fairly correlation with $\mathrm{m}=0.69$ and $l=0.42(\mathrm{r}=0.997)$ and those of equation (4) also displayed an excellent correlation with $\mathrm{m}=1.13, l=0.37$ and $\mathrm{h}=0.15(\mathrm{r}=0.998)$ as described in Table 3 . These results were similar for tert-butyl chloride (with $\mathrm{nl}=0.86$ and $l=0.38$ in hydroxylic solvents) ${ }^{33}$ which limits the $S_{: 1}$ pathway with strong electrostatic solvation and weak nucleophilic solvation of developing carbocation. even if those had shown more or less different values due to the resonance effect (improving the mi-value). The main reason to make a very good correlation with equation (2) as well as with equation (4) is that they could be responsible for the reduction of the contribution charge delocalization to the reaction site, compared with other solvent systems.

So we tried to plot $\log \left(k / k_{i j}\right)$ for solvolyses of 2 against $\left[0.69 \mathrm{Y}_{\mathrm{Cl}}+0.42 \mathrm{~N}_{\mathrm{T}}\right]$ in 27 solvents studied in this work (Figure 3) and [1.13 $\left.\mathrm{Y}_{\mathrm{Cl}}+0.37 \mathrm{~N}_{\mathrm{T}}+0.15 \mathrm{I}\right]$ in 18 solvents as well (Figure 4) to investigate dissection of kinetic data into the contributions from two competing reaction channels.

As shown in Figure 3 and 4 . both of these plots show a considerable deviation from the correlation line $\left(\mathrm{S}_{\mathrm{V}}\right)$ characteristic) and the approximate linearity of two forms for different binary solvent mixtures can be explained as a phenomenon caused by two competing reaction channels.

Figure 4 shows a very good correlation line for a polar media and for different binary solvent mixtures. a clear bilinearity (relatively to Figure 3 ) with distinct border lines

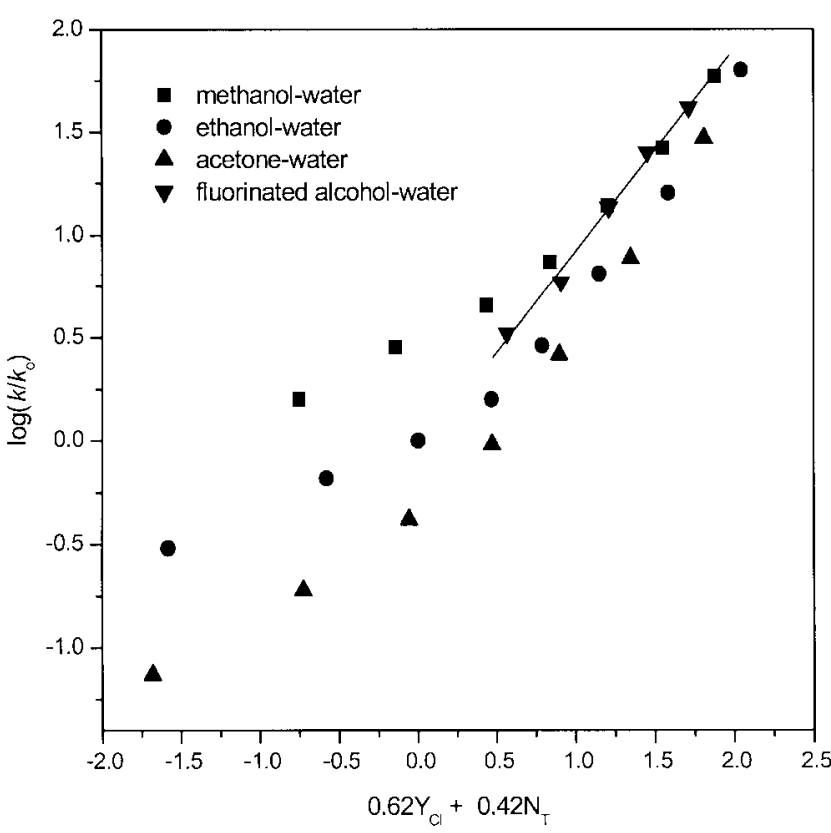

Figure 3. Plot of logarithms of rate constants for solvolyses of 2 at $25^{\circ} \mathrm{C}$ against $\left(0.69 \mathrm{Y} \mathrm{Cl}+0.42 \mathrm{~N}_{\tau}\right)$, detenmined from conelation $(\mathrm{r}=0.997)$ for fluorinated alcohol system.

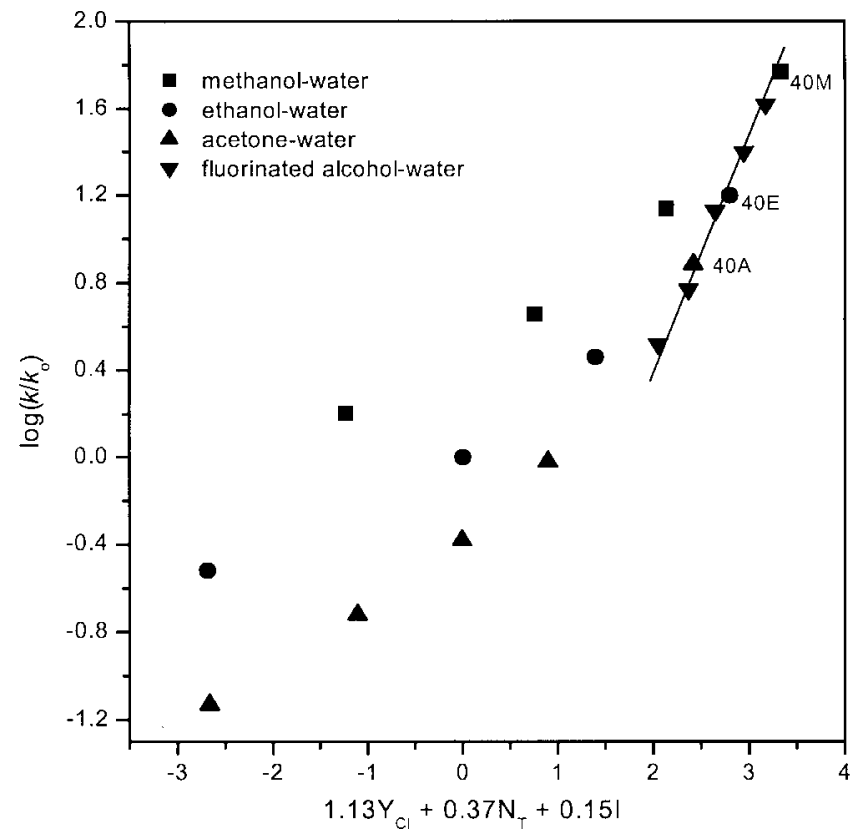

Figure 4. Plot of logarithms of rate constants for solvolyses of 2 at $25^{\circ} \mathrm{C}$ against $\left(1.13 \mathrm{Y}_{\mathrm{C}}+0.37 \mathrm{~N}_{\mathrm{T}}+0.15 \mathrm{I}\right)$, determined from correlation $(\mathrm{r}=0.998)$ for fluorinated alcohol system. (Limiting solvent composition of I parameters reported for aqueous media are $4(5) / v) \%$ methenol-water $(40 \mathrm{M}), 40(\mathrm{v} / \mathrm{v}) \%$ ethanol-water $(40 \mathrm{E})$ and $40(\mathrm{v} / \mathrm{s}) \%$ acetone-water $(40 \mathrm{~A}))$.

between the two pathways, considered to be a consequence of the resonance effect which distinguishes the change of mechanism according to the variation of solvent composition from the solvent effect.

From the results for polar media and the previously discussed results of the ratio $\left[k_{4, \mathrm{E}} / k_{97 \mathrm{~T}}\right]$ Y ratio term. we could 
understand that the process via the sane ionization mechanism ( $\mathrm{S}: \mathrm{L}$ ) controlled by solvent ionizing power mainly places $40 \%(\mathrm{v} / \mathrm{v})$ alcohol and $40 \%(\mathrm{v} / \mathrm{v})$ acetone with water solvent system on a correlation line of aqueous fluorinated solvent system. In contrast. for less polar media. the process can be explained as dispersion termis caused by the significant contribution from the charge delocalization as well as the nucleophility (N) to solvolyses rates (Figure 2). as investigated to undergo $S: 2$ mechanism in this work.

Kinetic solvent isotope effects (KSIE). KSIE has been noted as an appreciably disappointing mechanistic tool ${ }^{\hat{3} 3}$ for solvolyses because the same KSIE evidences a quite difference in mechanisnt. But these values can perform satisfactorily as an additional tool for mechanistic identification in solvolyses under favor of $/$ - value of solvent nucleophility (N). so KSIE. which was considered as the degree of cleavage of $\mathrm{MeO}-\mathrm{H}$ bond in rate determining step for methanolyses for $\mathbf{1}$ and 2 . were deternined and displayed in Table 6.

Our results obtained are considerable large values mechanistically that can be attributed to the nucleophilic solvation of TS through the breaking of $\mathrm{MeO}-\mathrm{H}$ (possible

Table 6. Rate constant $\left(\mathrm{s}^{-1}\right)$ and kinetic solvent isotope effect (KSIE) for solvolyses of 1 and 2 at $25^{\circ} \mathrm{C}^{\circ}$

\begin{tabular}{cccc}
\hline compound & $\mathrm{MeOH}$ & $\mathrm{MeOD}^{\delta}$ & $\left(k_{\mathrm{Me})} / k_{\mathrm{MeOD}}\right)^{c}$ \\
\hline 1 & $(1.61 \pm 0.02) \times 10^{-2}$ & $(1.17 \pm 0.01) \times 10^{-2}$ & 1.38 \\
2 & $(4.8 .3 \pm 0.03) \times 10^{-3}$ & $(3.19 \pm 0.02) \times 10^{-3}$ & 1.51 \\
\hline
\end{tabular}

"Determined conductimetrically at least in duplicate. ${ }^{\text {h }} \mathrm{MeOD}$ was Aldrich $\left(999.5 \pm{ }^{\circ} \circ \mathrm{D}\right)$. "Kinetic solvent isotope effect.

Table 7. Product selectivities [S, equation (7)] for solvolyses of the 2 in binary aqueous mixtures at $25^{\circ} \mathrm{C}^{\prime \prime}$

\begin{tabular}{|c|c|c|c|c|}
\hline \multirow{2}{*}{$\mathrm{v} / \mathrm{v}^{\mathrm{b}}$} & \multicolumn{2}{|c|}{ methanol/water } & \multicolumn{2}{|c|}{ ethanol/water } \\
\hline & [Ester $] /[$ Acid $]$ & $S$ & {$[$ Ester $] /[$ Acid $]$} & $S$ \\
\hline $98^{c}$ & 56.98 & 2.91 & 21.75 & 1.43 \\
\hline $95^{c}$ & 24.07 & 3.17 & 9.14 & 1.55 \\
\hline $92^{c}$ & 15.03 & 3.27 & 607 & 1.70 \\
\hline $90^{c}$ & 12.66 & 3.52 & 4.97 & 1.78 \\
\hline 80 & 5.16 & 3.23 & 2.40 & 1.93 \\
\hline 70 & 2.68 & 2.87 & 1.17 & 1.61 \\
\hline 60 & 1.43 & 2.38 & 0.69 & 1.48 \\
\hline 50 & 0.77 & 1.92 & 0.42 & 1.35 \\
\hline 40) & 0.44 & 1.67 & 0.23 & 1.13 \\
\hline 30 & & & 0.14 & 1.08 \\
\hline
\end{tabular}

"Analysed by reversed HPLC after the duration of reaction of half-life $(t: 2) \times 20$ fold (injecting $10 \mu \mathrm{L} 1^{\circ}$ is substrate in dry acetonitrile into $5 \mathrm{ml}$ of solvent ) and performed under the condition of measurement for selectivity $(S)$ as follows: wave length in UV-detector: $235 \mathrm{~mm}$. Eluent: $70^{\circ}$ of $(\mathrm{v}: \mathrm{v})$ methanol-water $+0.2^{\circ} .0$ (v) $\mu \mathrm{L}$, each response factor: 1.11 (methanol), 0.992 (ethanol). ${ }^{b}$ Actual composition by Karl-Fischer analysis: $98^{\circ} \circ$ methanol $=97.82^{\circ} \cdot 0.98^{\circ} \circ 0$ ethanol $=98.06^{\circ} \mathrm{m}, 95^{\circ} \mathrm{m}$ methanol $=94.800^{\circ} \mathrm{n}, 95^{\circ} \mathrm{m}$ ethanol $=94.38^{\circ} \circ$. $92^{\circ} \dot{i}$ methanol $=92.14^{\circ} i$ and $92^{\circ} \cdot{ }^{\circ}$ ethanol $=91.6^{\circ} i$ ethanol. ${ }^{\circ}$ Very moisture-sensitive 2 (Lancaster-AR: $99^{\circ} .0$ ) was distilled carefully under the condition of reduced pressure for selectivity value of solvents containing more than $90^{\circ} .0$ alcohol and distilled the 2 (stock solution) was stored into the desiccator containing nitrogen $\left(\mathrm{N}_{2}\right)$ gas. nucleophilic solvation by general base catalyzed type). The reason for the greater KISE value for 2 relatively to those for 1 are also consistent with the meaning of the $/$-values estimated by means of Grunwald-Wustein correlation analy ses

Rate-Product correlation. According to change in solvent composition of alcohol, product selectivities (S) determined from equation $(7)$ for solvolyses of $\mathbf{2}$ are represented in Table 7.

Maximum $S$ value in specified solvent composition of alcohol, which can generally appear in solvolyses with the mechanistic change over (dual reaction channel), were obtained and such results are very similar to those reported previously for solvoly ses of $5^{18 d}$ at $0^{\circ} \mathrm{C}$. (see Figure 5)

For solvolyses of $\mathbf{2}$ in highly alcoholic solvent composition. the $l$ - values ( $\mathrm{S}_{\$} 2$ character). a large-value of KISE ( 1.51 ) in pure methanol and the increase in selectivities (S), accordingly as water molecules are progressively added into pure alcohol solvent till $90 \% \mathrm{v} / \mathrm{v} \%$ methanol $(80 \% \mathrm{v} / \mathrm{v}$ ethanol) mixtures etc. such results so far obtained may be considerable evidence for the possibility of a substantial contribution from the third order reaction based on general base catalyzed by solvent molecule in less polar media, so that we could establish equation (8) having four possible third order reaction as shown below.

$$
k_{\mathrm{abs}}=k_{\mathrm{ww}}\left[\mathrm{H}_{2} \mathrm{O}\right]^{2}+k_{\mathrm{aa}}[\mathrm{ROH}]^{2}+\left(k_{\mathrm{aw}}+k_{\mathrm{wa}}\right)[\mathrm{ROH}]\left[\mathrm{H}_{2} \mathrm{O}\right]
$$

(First term, water acts as the nucleophilie. while another molecule of water acts as a general base. $k=k_{w}\left[\mathrm{H}_{2} \mathrm{O}\right]^{2}$. Second term. similarly. alcohol acts as the nucleophilie, while another molecule of alcohol acts as a general base. $k=$ $k_{\mathrm{aa}}[\mathrm{ROH}]^{2}$. Third term, alcohol acts as the nucleophile and molecule of water acts as general base. $k=k_{3 \mathrm{w}}[\mathrm{ROH}]\left[\mathrm{H}_{2} \mathrm{O}\right]$.

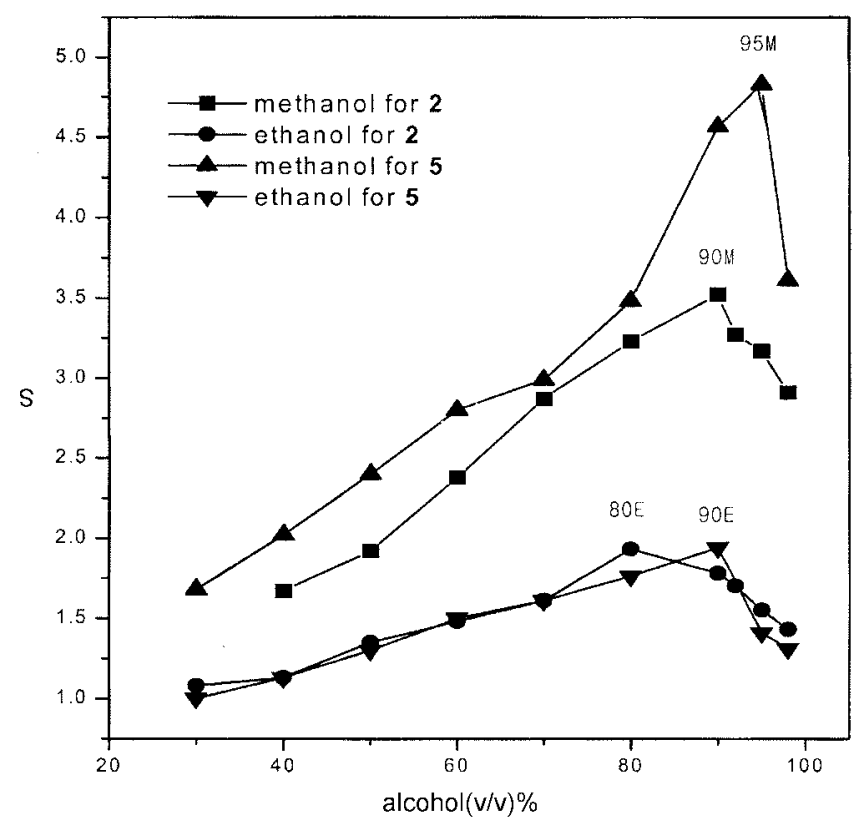

Figure 5. Plots of selectivities for solvolyses of 2 vs. solvent compositions of alcohol-water mistures at $25^{\circ} \mathrm{C}$ and compared to 5 (Data for 5 from ref. $18 \mathrm{~d}$ ). 
Finally, water acts as the nucleophile and a molecule of alcohol acts as a general base. $\left.k=k_{\text {par }}\left[\mathrm{H}_{2} \mathrm{O}\right][\mathrm{ROH}]\right)$.

The contribution from the $k_{p w}$ term $\left(k_{w w}\left[\mathrm{H}_{2} \mathrm{O}\right]^{2}\right)$ has been shown to be very small for solvolyses of carboxylic acid chlorides. ${ }^{14 a, 34}$ sulfonyl chlorides ${ }^{1+b}$ and phospherochloridate $^{15 \mathrm{~b}}$ in more rich alcohol content than about $80 \%(v / v)$ alcohol. If the $k_{\text {ww }}$ term were ignored. rate-product correlation between third order rate constant $k$ and selectivities. S could be given by equation (9) and (10)

$$
\begin{aligned}
& S=\frac{k_{\mathrm{aa}}[\mathrm{ROH}]^{2}+k_{\mathrm{aw}}[\mathrm{ROH}]^{2}\left[\mathrm{H}_{2} \mathrm{O}\right]}{k_{\mathrm{va}}\left[\mathrm{H}_{2} \mathrm{O}\right][\mathrm{ROH}]} \times\left[\mathrm{H}_{2} \mathrm{O}\right] /[\mathrm{ROH}](9) \\
& S=\left(k_{\mathrm{aw}} / k_{\mathrm{wa}}\right)\left(\left[\mathrm{H}_{2} \mathrm{O}\right] /[\mathrm{ROH}]\right)+k_{\mathrm{aa}} / k_{\mathrm{wa}}
\end{aligned}
$$

For more rich alcoholic solvents $(90-98 \mathrm{v} / \mathrm{\%} \%$ alcohol), we attempted to dissect the solvolyses rate of 2 into the contributions from three third order rate constants ( $k_{\text {ad, }}, k_{\text {aw }}$ and $k_{\text {wa }}$ ) using the plots for equation (10). The results obtained were presented in Table 8.

Good linear correlations strongly support the validity of the third order model proposed, and then a greater values (ca. 2-3 fold) of $k_{\text {ad }}\left(k_{\mathrm{av}}\right)$ and $k_{\mathrm{a} w} / k_{\mathrm{wa}}\left(k_{\mathrm{a}} / k_{\mathrm{wa}}\right)$, determined from the slopes (intercepts) of plots. for methanol-water mixtures relative to those for ethanol-water mixtures imply the dominance of nucleophilic attack on the TS. In case of $k_{\text {wa }}$ the small values for methanol-water are ascribed to a weak participation of nucleophilic attack by water molecule. supporting by methanol molecule as a general base. on the reaction center. For the ethanol-water system. we can understand that these rate constants shown in Table 8 were contributed to solvolyses of $\mathbf{2}$ as the similar nucleophilic magnitude. even if these values were more or less different.

Comparison of observed first order rate constant $(k)$ with first order constants $\left(k_{c a l}\right)$ are presented in Table 9 and the difference between $k_{\mathrm{cbs}}$ and $k_{\mathrm{cal}}$ is enhanced when water content increases. such a phenomenon is responsible for the medium effect on solvolyses rate (methanol-water system exhibits this effect greater than ethanol-water system). Consequently. the stabilization of TS for solvolyses of $\mathbf{2}$ in more rich alcohol content has relevance to the stoichiometric effect as well as the medium effect

Rate-Rate profile. In order to exclude the solvation effect

Table 8. Dissection of kinetic data into contribution from the third order model using rate-product correlation [equation (10)] for

\begin{tabular}{|c|c|c|c|c|c|c|c|}
\hline \multirow{2}{*}{$\begin{array}{l}\text { solvent } \\
(\mathrm{v} / \mathrm{v} \%)\end{array}$} & \multirow[b]{2}{*}{ slope } & \multirow[b]{2}{*}{ intercept } & \multirow[b]{2}{*}{$11^{a}$} & \multirow[b]{2}{*}{$r^{b}$} & \multicolumn{3}{|c|}{$10^{-1} \mathrm{M}^{-2} \mathrm{~s}^{-1}$} \\
\hline & & & & & $k_{a \mathrm{a}}{ }^{c}$ & $k_{a w}{ }^{d}$ & $k_{w-2}{ }^{p}$ \\
\hline methanol/water & 2.76 & 2.80 & 4 & 0.976 & 8.01 & 7.90 & 2.86 \\
\hline$(98 \mathrm{M}-90 \mathrm{M})$ & 2.94 & 2.79 & $y$ & 0.997 & 8.01 & 8.44 & 2.87 \\
\hline $\begin{array}{l}\text { ethanolwater } \\
(98 \mathrm{M}-90 \mathrm{E})\end{array}$ & 1.21 & 1.35 & 4 & 0.999 & 3.17 & 2.83 & 2.34 \\
\hline
\end{tabular}
solvoly tic reaction of 2 in highly alcoholic mixtures at $25^{\circ} \mathrm{C}$

"Number of solvent composition. ${ }^{\circ}$ Correlation coetficient. ${ }^{\circ}$ Calculated

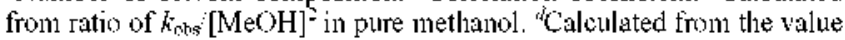
of slope after determining $k_{w a}$ tenn. "Calculated from the value of the intercept. 'Excepted for solvent composition of $92^{\circ}$ of $(\mathrm{v} \% \mathrm{~F})$ methanol-water.

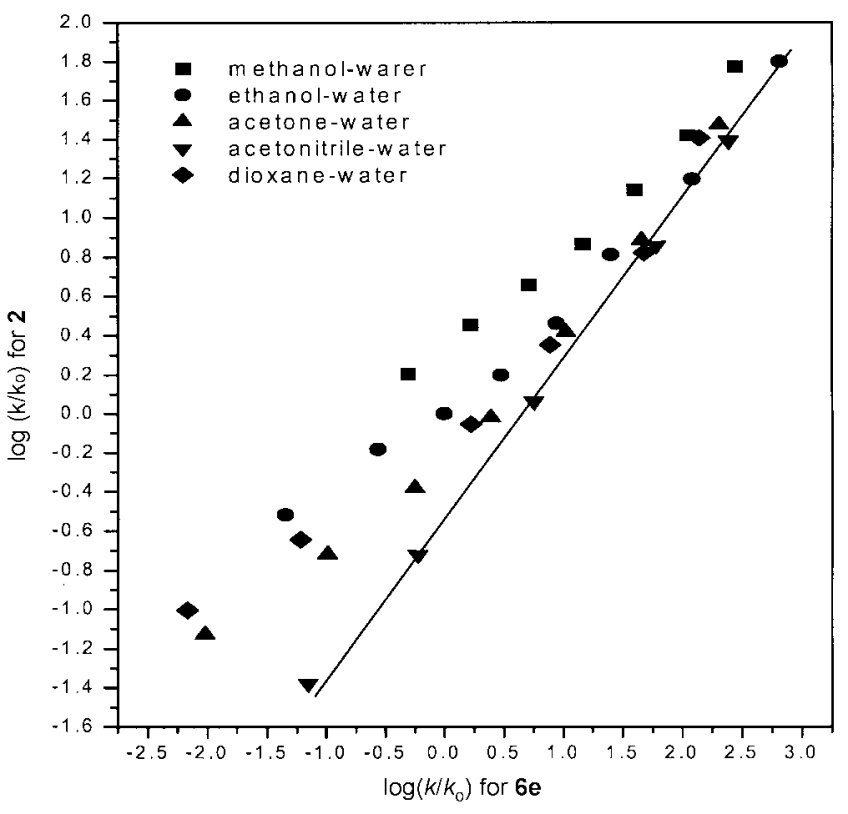

Figure 6. Plot of logarithms of rate constant for solvolvses of 2 is. rate for solvolyses of $6 \mathrm{e}$ at $25^{\circ} \mathrm{C}$ (Data for $6 \mathrm{e}$ from refs $8 a, 13,18 \mathrm{a}$ and 27).

occurring due to different solvation between aromatic and alkyl group and the electrophilic solvation caused by the difference in the reaction site structure $(\mathrm{COCl})$ adjacent to the leaving group $(\mathrm{Cl})$, logaritlums of rate constants for solvolyses of 2 in various aqueous solvent system $1 s$. corresponding rate constants for $\mathbf{6 e}$. recognized as limiting $\mathrm{S}_{\mathrm{l}} \mathrm{l}$ mechanism for acid chloride ${ }^{17 \mathrm{t}}$ were plotted (Figure 6).

Except for the acetonitrile-ivater system. following to the variation of each solvent composition the two separated lines of these plots suggest of two reaction channels, which was to be expected given our results discussed so far and a fairly good correlation $(r=0.9996)$ having 0.78 of slope for acetonitrile-water system is understood in terms of $S_{S} l$ pathway with a weak nucleophilic solvation of the developing carbocation.

In more rich media, this plot for the predominantly aqueous methanol systems (a greater acidity of methanol relative to ethanol) showed slight deviation (upper) from the straight line of the acetonitrile-water system. This means that the rate of ionization of the leaving group in solvolyses of $\mathbf{2}$ is faster than those of $\mathbf{6 e}$. indicating a difference in the contribution from electrophilic solvation of the developing anion $\left(\mathrm{Cl}^{-}\right)$.

On the other hand. the results obtained from rate - rate correlations (slope $=0.84 . r=0.987$ ) between solvolyses of 2 and $\mathbf{5}^{18 \mathrm{~d}}$ (Figure 7) are very consistent with our prior results. interpreted as dual reaction channel. Dispersion phenomena which are caused by the difference in solvation of aromatic ring and alkyl group is separated from those by dual reaction channel by this plot and this result with small dispersion obtained from this plot means that phenomena of dispersion in Grunwald-Winstein plots in solvolyses of $\mathbf{2}$ is primarily caused by mainly mechanistic change over. 


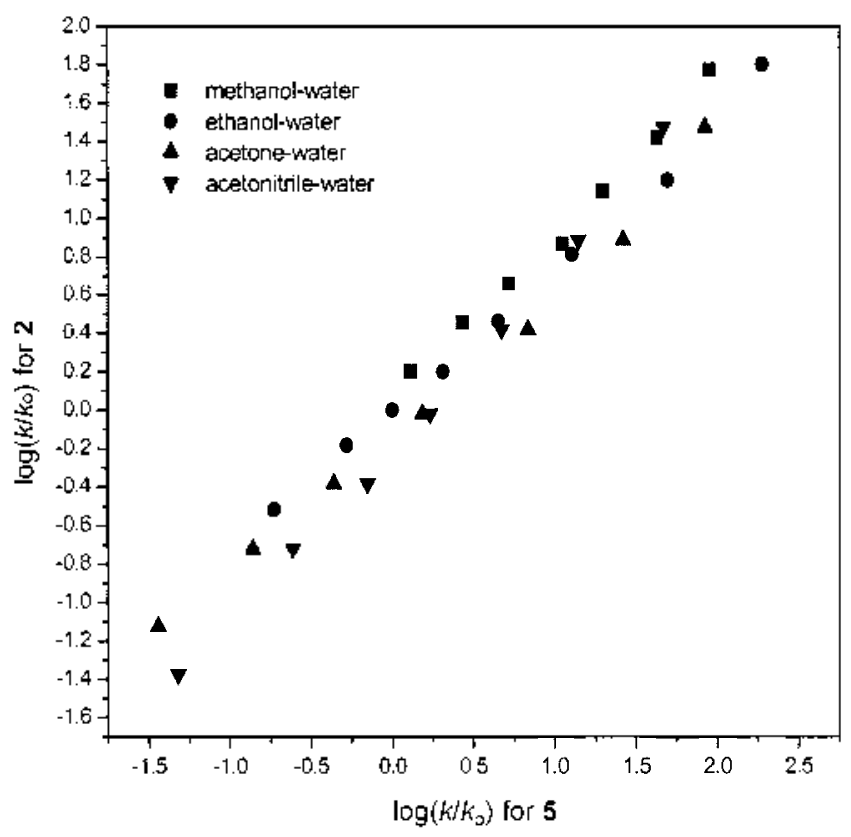

Figure 7. Plot of logarithuns of rate constant for solvolytic reaction of 2 at $25^{\circ} \mathrm{C} v \mathrm{~s}$. solvolytic reaction of 5 at $0^{\circ "} \mathrm{C}$ (slope $=0.84$, $\mathrm{T}=0.987$ ) (Data for 5 from ref. $18 \mathrm{~d}$ ).

Table 9. Comparison of the first order rate constant $(k)$ with the first order rate constant calculated $\left(k_{c a l}\right)$ from equation( $(8)$ in solvolyses of 2 at $25^{\circ} \mathrm{C}$

\begin{tabular}{cccccc}
\hline \multirow{2}{*}{$\begin{array}{c}\text { Solvent } \\
(\mathrm{v} / \mathrm{v} \%)\end{array}$} & \multicolumn{2}{c}{ methanol/water } & & \multicolumn{2}{c}{ ethanol/water } \\
\cline { 2 - 3 } \cline { 5 - 6 } \cline { 5 - 6 } & $\mathrm{k}$ & $k_{\text {ial }}^{a .5}$ & & $\mathrm{k}$ & $k_{\text {cal }}{ }^{a}$ \\
\hline 100 & $4.83 \times 10^{-3}$ & $4.83 \times 10^{-3}$ & & $0.918 \times 10^{-3}$ & $0.913 \times 10^{-3}$ \\
$98^{c}$ & $5.58 \times 10^{-3}$ & $4.94 \times 10^{-3}$ & & & \\
$95^{c}$ & $6.73 \times 10^{-3}$ & $5.09 \times 10^{-3}$ & & & \\
90 & $8.64 \times 10^{-3}$ & $5.30 \times 10^{-3}$ & & $1.99 \times 10^{-3}$ & $1.18 \times 10^{-3}$ \\
\hline
\end{tabular}

"Calculated using the third order rate constants determined $\left(k_{\mathrm{ag} .} k_{\mathrm{gw}}\right.$ and $k_{\text {wa }}$ ) as shown table 8 . "Calculated in case of 0.997 of correlation coefficient $(\mathrm{r})$ as shown in table 8. "Made up solution as described footnote $b$ in table 7

Conversely. a large $h$-value (1.2) obtained from this reaction can be responsible for the stabilization effect of carbocation for $\mathrm{S}_{\mathrm{X}} \mathrm{l}$-TS in highly aqueous media.

\section{Conclusion}

So far dispersion in Grunwald-Winstein plots for solvoly ses of 1 and 2 have been investigated in terms of multipleparameter correlation. selectivities(S) and rate-rate profile, etc:

For solvolyses of 1 , the main reason for dispersion phenomena is the dominant $\pi$-charge delocalization effect between developing carbocation of a reaction site and naphthoyl ring (resonance effect: 1, 2 of the h-value), as well as the weakly nucleophilic solvation effect of carbocation.

For solvolyses of 2 . a central role for this dispersion corresponds to mechanistic change. And the large h-value (1.2) obtained is attributed to the $S_{\aleph} l-S_{\star} 2$ mechanistic spectrum.

A distinct borderline between $S_{N} 1$ and $S_{.4} N / S_{N} 2$ pathways is obtained from these rates, using the result obtained from multiple Grunwald-Winstein correlation in fluorinated alcohol-water system.

Third order rate constants ( $k_{\mathrm{aa}} . k_{\mathrm{aw}}$ and $k_{\mathrm{wa}}$ ) for solvoly ses of 2 in more rich alcohol mixtures were determined from plots of equation $(10)$. which demonstrates the validity of the third order model: a large shift away from stoichiometric effects to dominant medium effects on solvation of the reaction center was also shown. as water is added to an alcohol solvent.

Solvolyses of 1 are up to 20 times faster than those of 2 in more polar solvent (Table 1 and 2) and this can be explained by the delocalized cation (Scheme 2) fonmed from 1. In less polar solvents. the rate of 2 is increase relative to 1 because a second mechanism also operates.

\section{Experimental Section}

Materials. Solvents for kinetics in this paper were dried and distilled by standard methods except for dioxane and hexafluoro-iso-propanol (HFIP). dioxane (TCI-GR) used without distillation and aqueous mixtures were prepared by mixing appropriate volumes at ambient temperatures, the accurate water contents of $97 \%(w / w)$ trifluoroethanol-water mixtures, determined by Karl Fischer titration using a Mettler-Toledo DL18 apparatus, 1- and 2-naphthoyl chloride (Lancaster-AR: 99\%) was used after investigating its purity by using reversed HPLC.

Kinetic methods. For methanol-water. ethanol-iwater. and fluorinated solvent-water mixtures. kinetic data were collected conductimetrically using a high precision digital voltmeter (Solartron 7066 Datastore). which was set up under computer control (BBC Master Microcomputer) to collect up to 50 reading from a stirred conductivity cell to solve the problem for solubility in high aqueous media. For other solvent mixtures. the rate constant was determined using a general conductimetrical method

Acknowledgment. We are grateful to EPSRC (UK) for funancial support (for Kinetics. HPLC and Karl-Fischer Titration), to Dong-Eui University for research grants and to Llewellyn. $\mathrm{G}$ for helpful experimental works.

\section{References}

1. Grunwald. E: Winstein, S. J. Am. Chem. Soc. 1948,70,846.

2. Bentley. T. W.: Llewellyn. G. Prog. Phns. Org. Chem. 1990. 17. 121 .

3. Takeuchi. K.: Ohga. Y.: Ushino. T.: Takasuka. M. I. Org. Chent. $1997.62,4904$.

4. Koo, I. S.; Yang. K; Oh. H. K.: Lee, I. Bull Korean Chem. Soc. 1996. 17, 491 .

5. Kevill. D. N.: DSouza. M. T. J. Phus Org Chemt 1992.5.287.

6. (a) Schadt. F. L.: Bentley. T. W.: Schleyer. P. v. R. J. An Chen Soc. 1976. 98. 7667. (b) Bentley. T. W.: Schleyer. P. v. R. Ads: Phs. Org. Chem 1977, 1t, 1. (c) Liu. K.-T. J. Chinese Chem. Soc. 1995. 42,607

7. (a) Kevill, D. N.: Anderson, S. W. J. Org. Chem. 1991, 56. 1845 
(b) Ketill, D. N.: D Souza, M. J. J. Chem. Resfs). 1993. 174. (c) Kevill. D. N. In Adrances in Quantitative Structure-Property Retationships: Chorton. M.. Ed.: IAI Press: Greenwich. CT. 1996: Vol 1.p 81 .

8. (a) Bentlev: T. W.: Koo, I. S.: Nonnan. S. I. J. Org (chem. 1991. 56. 1604. (b) Bentley. T. W: Dau-Schnidt. I.-P: Llewellyn. G: Mavr H. J. Org. Chem 1992. 57.2387.

9. (a) Liu. K.-T.: Sheu. H.-I.: Chiu. P.-F.: Hu. C.-R. Tetrahedron Lett. 1990. 31.3611. (b) Liu. K.-T. J. Org. Chem. 1991. 56. 3021.

10. Kevill. D. N.: Ismail. N. HJ.: D'souza. M. J. J. Org. Chem. 1994. 59.6303 .

11. Kevill. D. N.: D'Souza, M. J. J. Chem. Resisf. 1996. 1649.

12. (a) Fujio, M: Saeki. Y: Nakamoto, K: Yatsugi, K.: Goto. M.: Kim. S. H.: Tsuji. Y.: Rapport. Z: Tsuno. Y. Bull. Chem. Soc. Jpn. 1995. 68. 2603. (b) Fujio. M.: Susuki. T: Yatsugi. K.: Saeki. Y: Goto. N.: Kim. S. H.: Tsuji. Y: Rapport. Z.: Tsuno. Y. Bull. Chent Soc. Jpn. 1995. 68, 2619

13. Bentley. T. W: Harris, H. C: Koo. I. S. J. Chem. Soc. Perhin Trans. $21988,2,783$.

14. (a) Bentley. T. W.: Jones. R. O. J. Chem. Perkin Trans. 21993. 2351. (b) Bentley. T. W.: Jones. R. O.: Koo. I. S. J. Chent. Soc. Perkin Trans. 2 1994. 753.

15. (a) Bentlex: T. W. Ryu. Z. H. J. Chem. Soc. Perhin Trans. 21994. 761. (b) Bentley. T. W.: Ebdon. D: Llewellyn. G.: Abduljabor. M. H.: Miller, B.: Kevill. D. N. J. Chrm. Soc. Dallon Trans. 1997. 3819.

16. Bentley. T. W. Carter. G. E.: Harris. H. C. J. Chem. Soc. Perkin Trans. 21985.983

17. (a) Karton, Y: Process, A. J. Chem. Soc. Perkin Trans. 21978. 295. (b) Bentley. T. W. Koo. I. S. J. Chem. Soc. Pertin Trans. 2 1988.785

18. (a) Bentley. T. W.: Koo. I. S. J. Chent. Soc. Perkin Trants. 21989. 1385. (b) Koo. I. S.: Bentley. T. W.: Llewellyn. G.: Kang. D. H.: Lee. I. J. Chent Soc. Perkin Trans. 2 1991 175. (c) Koo. I. S.: Bentley. T. W. Llewellyn. G.: Noman. S. J. Groatia Chemica Acta 1992, 65(3). 575. (d) Bentles, T. W.: Shim. C. S. J. (Chem. Soc. Perhim Trans. 21993,1659

19. (a) Lee. I.: Sung. D. D.: Uhm. T. S.: Ryu. Z. H. J. Chem. Soc.
Perkin Trans. 2 1989. 1697. (b) Sung. D. D.; Kim, Y. H.: Park, Y. M.: Ryu. Z. H.: Lee. I. Bull. Korean Chent. Soc. 1992. 13, 599.

20. (a) Capont. B.: Ghosh. A. K.: McL. A. Acc. Chent Res. 1981. It. 306. (b) MeClelland. R. A.: Santry. L. T. Acc. Chem. Res. 1983. 16. 394 .

21. Kevill. D. N.: D'Souza. M. J. J. Chem. Soc. Perkin Trans. 21997. 1721 .

22. (a) Bender. M. L.: Chen. M. C. J. Am. Chem. Soc. 1963. 85. 1626. (b) Olah. G. A.: O'Brien. D. H.: White. A. M. J. Ant. Chem. Soc. 1967. 89. 5694. (c) William. A.: Dogulas. K. T. Chent. Rev: 1975. 75.627 .

23. (a) Kivinen, A. The Chemisty of Acyl Halides. Patai, S. Ed. Interscience: New York, 1972: Ch. 6. (b) Page. M.: Wiliams. A Organic and Bio-Organic Mechanisms: Longman: 1997: Ch. 7. 145 .

24. Fujio. M.: Kim. H.-J: Tsuno. Y. Presented in part at Kunshu Intemational Symposim on Plysical Organic Chemisoy (KISPOC-VIII): Japan. Sept. 1999.

25. Liu. K.-T. Chen, H. I. Presented in part at Kynshu International Synpositm on Phosical Organic Chentistry (KISPOC-VII): Japan1. Sept. 1999

26. Kevill. D. N.: D'Souza. M. T. . Chent Res. (M) 1996. 1649.

27. Bentley. T. W.: Harris, H. C. J. Chem. Soc. Perkin Trans. 21986. 619.

28. Bentley. T. W. Llewellyn, G.: Ryu, Z. H. J. Org. Chm. 1998. I4. 4654 .

29. (a) Fainberg. A. H.: Winstein. S. J. Am. Chem. Soc. 1956. 78, 2770. (b) Fainberg. A. H.: Winstein. S. J. An. Chent Soc. 1957. 79. 1597.

30. Raber, W. C.: Neal. Jr.: Dukes, M. D.; Harris, J. M.; Mount, J. . . Am. Chem. Soc. 1978, 8137.

31. Bentley. I. W. Harris. H. C. J. Org. Chent 1988.5.725.

32. Kevill. D. N.: DSouza. M. T. J. Chent. Res. (S) 1993. 174

33. Laughton. P. M.: Robertsonl. R. E. In Solute-Sohent Interaction: Coetzee, J. F, Ritchie, C. D., Eds: 1969: p 424

34. (a) Koo. I. S.; Yang, K. Y.: Kang, K.: Lee. I. Bull Korean Chem. Soc. 1989. 9. 948. (b) Koo. I. S.; Yang. K. Y:- Kang. K.; Lee. I.; Bentley. T. W. J. Chent Soc. Perkin Thans. 2 1989. 1179. 